\title{
An assessment of the reproduction, predation, and nesting behavior of Sulawesi Masked-owl (Tyto rosenbergii) in oil palm plantation: A case study of West and Central Sulawesi, Indonesia
}

\author{
ADE NENDI MULYANA ${ }^{1, \vartheta}$, SWASTIKO PRIYAMBODO ${ }^{2, \bullet \vartheta}$, HERMANU TRIWIDODO ${ }^{2}$, \\ HENNY HENDARJANTI ${ }^{3}$, BANDUNG SAHARI ${ }^{3,4}$ \\ ${ }^{1}$ Program of Integrated Pest Management, Graduate School, Institut Pertanian Bogor. Jl. Raya Dramaga, IPB University Campus, Bogor 16680, West \\ Java, Indonesia. Tel.: +62-251-8622642. `email: Nendi_71@apps.ipb.ac.id \\ ${ }^{2}$ Department of Plant Protection, Faculty of Agriculture, Institut Pertanian Bogor. Jl. Meranti, IPB University Campus Dramaga, Bogor 16680, West \\ Java, Indonesia. Tel.: +62-251-8622642, “wemail: swastiko@apps.ipb.ac.id \\ ${ }^{3}$ PT. Astra Agro Lestari Tbk. Pulogadung Industrial Area, East Jakarta 13920, Jakarta, Indonesia \\ ${ }^{4}$ Center for Transdisciplinary and Sustainability Science, Institut Pertanian Bogor. Jl. Raya Dramaga, IPB University Campus, Bogor 16680, West Java, \\ Indonesia
}

Manuscript received: 16 August 2020. Revision accepted: 21 November 2020.

\begin{abstract}
Mulyana AN, Proyambodo S, Triwidodo H, Hendarjanti H, Sahari B. 2020. An assessment of the reproduction, predation, and nesting behavior of Sulawesi Masked-owl (Tyto rosenbergii) in oil palm plantation: A case study of West and Central Sulawesi, Indonesia. Biodiversitas 21: 5685-5689. The quality and quantity of yield in palm plantations are reduced due to inevitable factors such as pests, diseases, and weeds. Furthermore, owls (Tytonidae) play a role as potential predators to control rats, the major pest. Therefore, this study aims to observe the reproduction patterns, predation, and nesting behavior of Tyto rosenbergii. To achieve this, direct observation and the installation of a camera trap in the nest box was adopted. Furthermore, a predation test was carried out by feeding the owls with rats daily in a cage measuring $4 \mathrm{~m} \times 8 \mathrm{~m} \times 6 \mathrm{~m}$. The results showed that the number of eggs produced ranged from 2 to 6 , with an average of 3.85. Also, the Percentage of hatching ranges between $0-100 \%$ with an average of $80.77 \%$, and that of chicks that survive to the fully feathered is $51 \%$. In addition, $T$. rosenbergii was able to prey on 1-4 rats per night, and its activity mostly occurs outside the cage than inside, except when they had a reproductive season.
\end{abstract}

Keywords: Biological control, eggs, nest box, predator, prey

\section{INTRODUCTION}

Indonesia is the world's largest palm oil producer, with an export contribution of $55.78 \%$ (Oil World 2019). One of the biggest obstacles in the production process is the infestation of rats at all oil palm plantation stages, including nurseries, immature, and mature plants. The symptom of rat attack on oil palm fruit is in the form of cut marks. Furthermore, the estimated loss due to this attack ranges from $5-10 \%$ of the total yield (Wood and Fee 2003). Meanwhile, the dominant rat species found in oil palm plantations are Rattus tiomanicus and $R$. tanezumi (Verwilghen 2015; Ikhsan et al. 2020).

Various efforts to manage rats in oil palm plantations include technical, physical, mechanical, sanitary, biological, and chemical control. Furthermore, synthetic chemical rodenticides' continuous use to manage rats has negative impacts, which causes resistance (Horak et al. 2015) and leads to wrong target because they are eaten by non-target animals/organisms (Elliot et al. 2014). To overcome this, many rat control in oil palm plantation uses Tyto alba, a natural enemy of rats by providing nest boxes on oil palm plantation for this species to live and breed.

Tyto alba is one of the Tytonidae family species, which is widely bred to control rat pests in various agricultural commodities such as rice and oil palm. They are active at night to hunt rats, small animals, and other wild birds (Rabou 2019). This species has a wide distribution (Taylor 1994), with small mammals being the dominant prey (Hovarth et al. 2018; Milchev 2015; Syaufi et al. 2020; Marti 2010) and are bred in oil palm plantation by making nest box. This is evident to Bank et al. (2019) that the installation of the nest box is a measure in maintaining the owl population. Furthermore, artificial buildings provide suitable nesting sites for various bird species (Mainwaring 2015), especially with feed availability. Nest boxes are generally made of wood and are installed in the middle of an oil palm plantation. Also, Barn owls are very selective in choosing the nest box to be occupied (Abidin et al. 2016). According to Wendt and Johnson (2017), owls are more attracted to wooden boxes because they are similar to natural nesting cavities in trees.

The use of $T$. alba is currently a recommendation for rat control in oil palm plantation because it is proven to be effective in suppressing fruit damage below the economic threshold (Rajagukguk 2014). However, local species' use also needs attention, especially in the Sulawesi region, which has a different owl species. Tyto rosenbergii (Sulawesi Masked-owl), a close relative of the Barn owl ( $T$. alba) but has a relatively larger body size, is endemic Sulawesi Island. 
The habitat of this includes rainforests, shrubs, forested areas near human settlements, grasslands, and cultivated areas such as plantations (BirdLife International 2016). However, only a few studies have reported $T$. rosenbergii to control rat pests in an oil palm plantation in Sulawesi. Therefore, the available information is still limited to its biology and ability to prey on rats. Consequently, this study focused on examining the reproductive patterns, predation, and nesting behavior of the Sulawesi Masked-owl ( $T$. rosenbergii) in oil palm plantations. The results are expected to become a reference for using the Sulawesi Masked-owl (T. rosenbergii) as a biological control agent for rat pests in an oil palm plantation in Sulawesi.

\section{MATERIALS AND METHODS}

\section{Time and place of research}

The research was conducted from July 2019 to January 2020 in an oil palm plantation located in Towiora Village, Rio Pakava District, Donggala Regency, Central Sulawesi and Martasari Village, Pedongga District, Pasangkayu Regency, West Sulawesi.

\section{Reproduction study of Sulawesi Masked-owl (Tyto rosenbergii)}

Observation of reproductive patterns was carried out directly in the nest box at the study site. Nest boxes are generally built in the middle of oil palm plantations as breeding houses for Sulawesi Masked-owl. They are made of wood, measuring $1 \mathrm{~m} \times 0.5 \mathrm{~m}$ x $0.6 \mathrm{~m}$. In this study, 55 nest boxes spread over 16 plantation blocks with a total area of 529.53ha were observed. Also, the observed variables include reproductively active nest boxes, namely the number of nest boxes with unhatched eggs, number of eggs per nest box, hatching of eggs, and hatching interval between eggs in the same nest box. Furthermore, observations were made every two days when the eggs were not hatched every two days. However, when one egg has hatched, the rest are observed daily until all the eggs hatch to see the hatching interval between eggs.

\section{Chicks growth and development}

The development of $T$. rosenbergii chick was seen from the time the eggs hatches until it is fully feathered and able to fly ( 8 weeks old). The variables observed were the number and age of chicks that died and those that survived until eight weeks. Observations were carried out directly on the nest box at intervals of once a week.

\section{Predation rate of Sulawesi Masked-owl (Tyto rosenbergii)}

The test to determine the predation level was carried out on three owls taken from the field. The criteria for testing the owls is the ability to fly and hunt their prey. The test was carried out on a $4 \mathrm{~m} \times 8 \mathrm{~m} \times 6 \mathrm{~m}$ cage containing nest boxes. Before this, the owls were adapted in the test cage for two weeks and each individual was tested for four days by feeding with a minimum of five rats daily. In this case, the variable observed was the number of rats that were preyed on per night.

\section{Nesting behavior study of Sulawesi Masked-owl (Tyto rosenbergii)}

The nesting behavior of $T$. rosenbergii was observed to determine the presence and activity of owls in the nest box. This was made based on three criteria: nest box without eggs and chicks, eggs, and chicks. The observations were made using a camera trap, set on video mode and mounted inside the nest box. Each criterion was chosen by three nest boxes with observations on each for 72 hours $(3 \times 24$ hours). Each video was 10 seconds long with 10-minute intervals between videos.

\section{Data analysis}

The data is processed in tabulated form and graphs using Microsoft Excel 2016 and then described. Furthermore, the correlation between the number of eggs per nest box and the success rate of the chicks to mature was analyzed by Pearson correlation using Minitab 2016.

\section{RESULTS AND DISCUSSION}

\section{Reproduction study of Sulawesi Masked-owl (Tyto rosenbergii)}

From a total of 55 nest boxes observed, 22 (40\%) were being in the breeding phase (unhatched eggs). Furthermore, 104 oval and white eggs were observed from 22 nest boxes. The number of eggs produced in a reproductive period ranges from 2-6 per nest box with an average of 3.85 (SD = 0.98) as shown in Figure 1. Schott (2016), reported that the number of $T$. rosenbergii eggs produced in one reproduction ranges from 2-3.

Factors that play an important role in breeding owls include food availability, weather (Chausson et al. 2013) and habitat conditions, predation risk, agricultural activities, diseases, and nest box placement (Adejumo 2019). Furthermore, the number and quality of eggs produced are influenced by nutritional factors during the formation period (Nager 2006). When food is abundant, birds reproduce well. However, in conditions of food shortage, the female owls sometimes do not lay eggs at all (Taylor 1994)

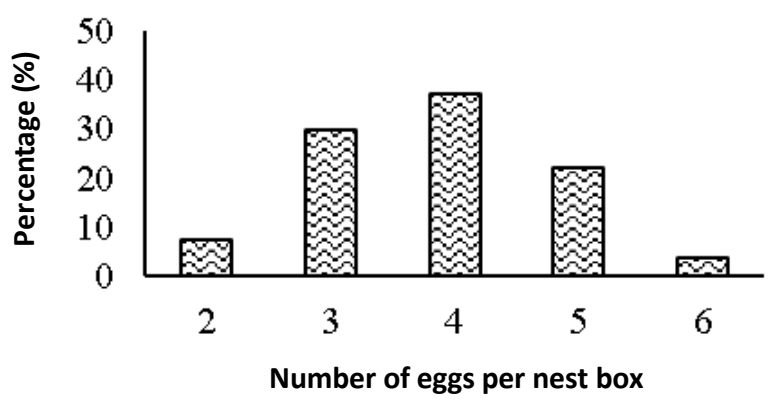

Figure 1. Distribution number of eggs 
Biotic and abiotic factors influence the success of hatching eggs. The average hatching percentage of $T$. rosenbergii eggs is $80.77 \%$, the rest did not hatch due to missing or rotting eggs (Figure 2). According to Abidin et al. (2017), the success rate of hatching $T$. alba eggs ranges from $0-83 \%$. In this study, the lenght of the incubation process was not exactly known. However, Scott (2016) reported that the incubation of $T$. rosenbergii eggs ranges from 35-42 days.

The observation results indicated that there were significant differences in egg hatching time and the interval ranges from 1-5 days. Bunn and Warburton (1997) reported that the hatching interval between eggs varies from 2-3 days, depending on when they are laid. Furthermore, owls lay eggs at 2-3 day intervals and sometimes longer such that the hatching process does not coincide (Taylor 1994). The mother incubates the eggs until they are all hatch. Also, the different hatching time results in the young's various size and age in a nest box. The results of observations show that two breeding periods occurred in the same nest box (Table 1).

Table 1 showed that there were two breeding periods for the same five nest boxes. According to Bunn and Warburton (1997) when food is abundant birds usually lay their eggs immediately. Furthermore, the results of observations in breed interval from the previous period were 4-5 months. However, in nest box OC 14-1 and OC 91 , breeding from the previous period was only 1-2 months apart. This is because all the eggs in nest box OC 14-1 were lost before hatching and all the chicks in OC 9-1 were lost. Therefore, it is believed that this triggered the owls to lay eggs again immediately. However, further research is required to determine this.

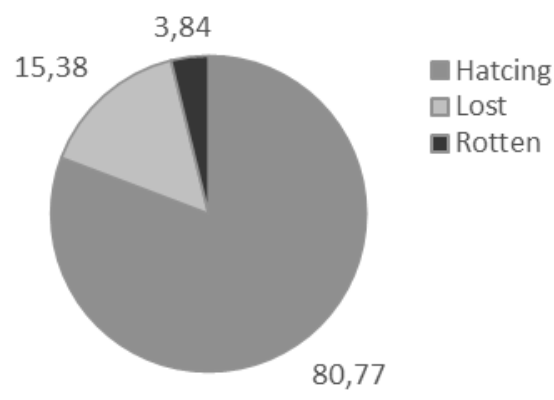

Figure 2. Successful hatching of eggs. $N=104$

\section{Chicks growth and development}

Field observations showed that the chicks had full feathers at eight weeks after hatching. At this age, birds learn to fly and hunt their prey around the nest box. Furthermore, not all chicks were able to survive until they were fully feathered. The percentage that survived to fully feathered was $51 \%$ (Figure 3).

Many deaths/chicks were missing at less than three weeks of age (Figure 4). Also, the death of owls occurred within the first 20 days after the eggs hatch. The last chick usually loses food competition and is generally smaller than the first (Taylor 1994). Furthermore, the survival of chicks is greatly influenced by environmental factors.

One of the factors that are suspected to be the cause of a chick's inability to survive include competition for food when it is limited. The smallest are usually unable to compete with the biggest, however, when the food is available, all the chicks tend to survive (Adejumo 2019).

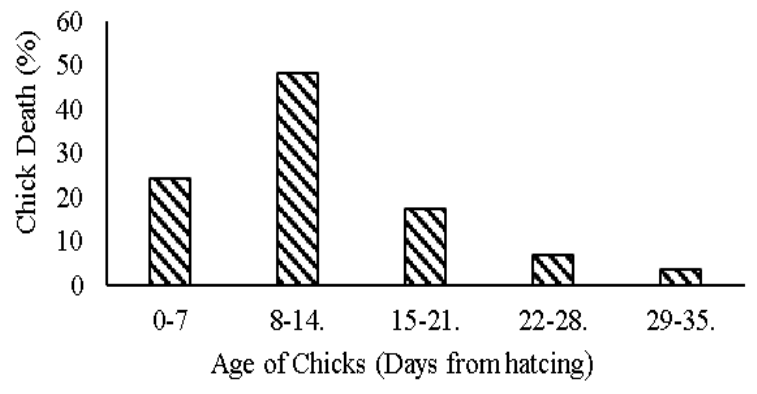

Figure 4. Age of chicks vulnerable to disappearance/death (N dead chicks $=29$ individuals)

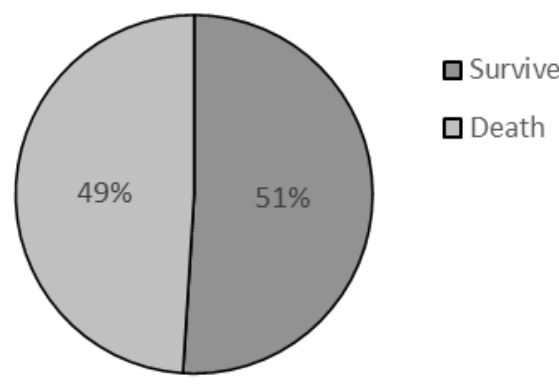

Figure 3. Chicks development. $\mathrm{N}=59$

Table 1. Breeding period for Sulawesi Masked-owl (T. rosenbergii) on the same nest box during the study

\begin{tabular}{|c|c|c|c|c|c|c|c|}
\hline \multirow{2}{*}{$\begin{array}{l}\text { Nest box } \\
\text { code }\end{array}$} & \multicolumn{3}{|c|}{$\mathbf{1}^{\text {st }}$ Period } & \multicolumn{3}{|c|}{$2^{\text {nd }}$ Period } & \multirow{2}{*}{$\begin{array}{c}\text { Breed } \\
\text { interval } \\
\text { (month) }\end{array}$} \\
\hline & $\begin{array}{l}\text { Month of } \\
\text { breeding }\end{array}$ & $\begin{array}{c}\text { Number of } \\
\text { eggs }\end{array}$ & $\begin{array}{c}\text { Hatching } \\
\text { percentage }(\%)\end{array}$ & $\begin{array}{l}\text { Month of } \\
\text { breeding }\end{array}$ & $\begin{array}{c}\text { Number of } \\
\text { eggs }\end{array}$ & $\begin{array}{c}\text { Hatching } \\
\text { percentage }(\%)\end{array}$ & \\
\hline OC $15-3$ & June & 5 & 80 & November & 6 & 66.66 & 4 \\
\hline OC $25-1$ & July & 4 & 100 & November & 5 & 100 & 5 \\
\hline $\mathrm{OH} 2-4$ & June & 4 & 50 & November & 3 & 100 & 4 \\
\hline OC 14-1 & October & 5 & 0 & December & 3 & 100 & 1 \\
\hline OC 9-1 & September & 4 & 75 & November & 5 & 100 & 2 \\
\hline
\end{tabular}




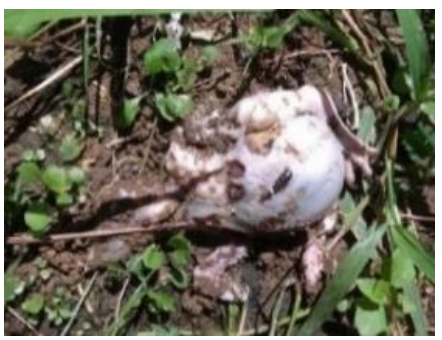

A

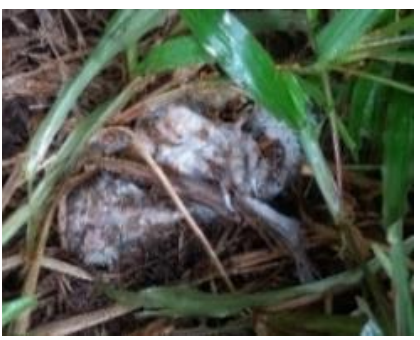

B

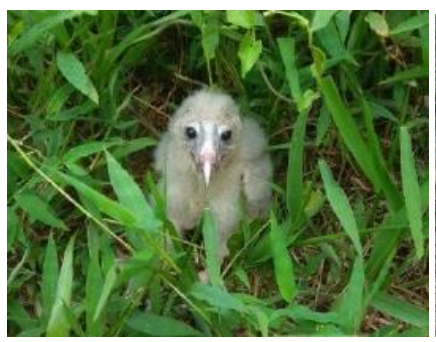

C

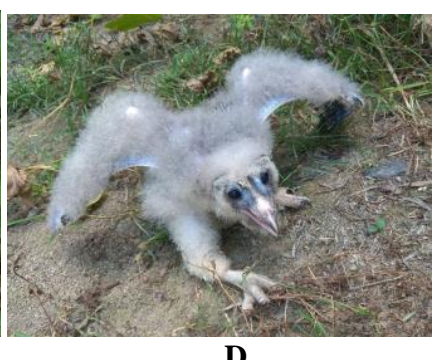

D

Figure 5. Chick of Tyto rosenbergii falling from the nest box: A-B. Dies, C-D. Live

Table 2. Predation rate of the Tyto rosenbergii

\begin{tabular}{ccccc}
\hline Owl & Sex & $\begin{array}{c}\text { Testing } \\
\text { time }\end{array}$ & $\begin{array}{c}\text { Number of } \\
\text { rats }\end{array}$ & $\begin{array}{c}\text { Number of } \\
\text { rats preyed }\end{array}$ \\
\hline Individual 1 & Male & $1^{\text {st }}$ night & 6 & 3 \\
& & $2^{\text {nd }}$ night & 7 & 2 \\
& & $3^{\text {rd }}$ night & 12 & 4 \\
Individual 2 & \multirow{2}{*}{ Female } & $4^{\text {th }}$ night & 11 & 1 \\
& & $1^{\text {st }}$ night & 12 & 3 \\
& & $2^{\text {nd }}$ night & 10 & 3 \\
& & $3^{\text {rd }}$ night & 6 & 3 \\
Individual 3 & \multirow{2}{*}{ Female } & $4^{\text {th }}$ night & 7 & 2 \\
& & $1^{\text {st }}$ night & 5 & 1 \\
& & $2^{\text {nd }}$ night & 10 & 3 \\
& & $3^{\text {rd }}$ night & 10 & 4 \\
& & $4^{\text {th }}$ night & 6 & 1 \\
\hline
\end{tabular}

Furthermore, the correlation analysis between the number of eggs per nest box and the surviving chicks showed a coefficient of 0.339 with a P-value of 0.133 . This indicates a weak positive relationship (not significant) between the number of eggs per nest box and the surviving chicks. The more eggs produced a result in increased the number of surviving chicks. However, this is greatly influenced by environmental factors, especially the availability of food. Another factor that causes death is the chicks falling from the nest box before it can fly such that it becomes easier for predators to prey because of the parent's inability to bring the chick back into the nest box (Figure 5).

\section{Predation rate of Sulawesi Masked-owl (Tyto rosenbergii)}

The observations on the level of owl predation against rats in the experimental cage showed that $T$. rosenbergii could prey on 1-4 rats per night (Table 2). However, in inbreeding conditions, the number of prey killed and brought into the nest box is presumably because they have to feed the chicks. Adejumo (2019) reported that parent owls provide food until the chicks can hunt independently at around 10-12 weeks after hatching.

The result of these observations indicates that $T$. rosenbergii has the potential to be used as a biological control agent for rat pests in oil palm plantations. This is in accordance with the statement of Rajagukguk (2014) that the use of owls in oil palm plantations has been proven to be effective in controlling rat pests such that fruit damage

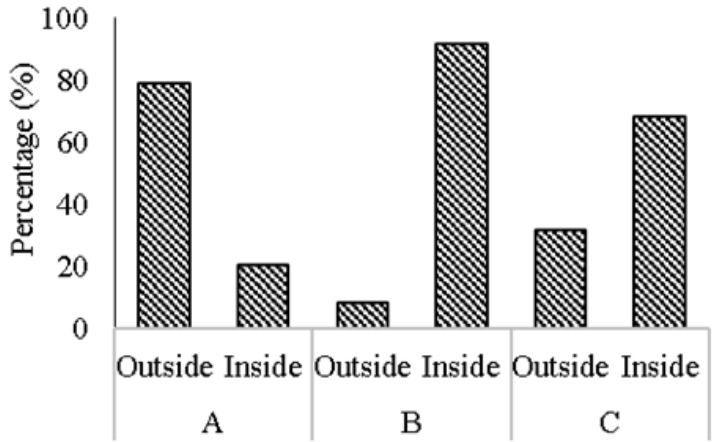

Figure 6. Nesting behavior of Tyto rosenbergii in nest box. A. Nest box without chicks and eggs, B. Nest box with eggs, C. Nest box with chicks

is below the economic threshold (less than 5\%). Furthermore, the main prey of $T$. rosenbergii includes rats, small rodents, and bats (Scott 2016). Also, Puan et al. (2011) reported that $T$. alba preys on small mammals, especially rodents in oil palm plantations. The feeding behavior of owls is by tearing the prey apart, except for the small-sized that is swallowed as a whole. According to Syaufi et al. (2020), T. alba has a preference for medium prey. Also, owls cannot digest all the food they eat, therefore, they regurgitate some as pellets.

\section{Nesting behavior study of Sulawesi Masked-owl (Tyto rosenbergii)}

The results showed that the parent owls rarely enter the nest box containing no eggs or chicks, therefore, most activities are carried out outside the box. However, they spend more time in the nest box during breeding because they have to incubate or take care of the young chicks (Figure 6).

The parents are not always in the nest box containing chicks, however, they usually return to feed their young. Furthermore, the chicks make a hissing sound when they are looking for their parents to ask for food. In addition, the parents shred the prey and then feed it to the young. When owls are not actively reproducing, they do more activities outside of the nest box and return at night. Moreover, eating and mating activities are carried out both inside and outside the nest box. 
When laying eggs, it is suspected that male individuals are more active in hunting than females. This is because the female is always in the nest box to incubate the eggs. Video recordings from camera traps show that males carry prey to the nest box and then feed them to females. Furthermore, during the breeding season, males provide the bring prey to be given to females, which are laying eggs or incubating, with preys for feeding (Durant et al. 2013; Datta 2019). However, they both hunt during the rearing period to meet their food needs (Taylor 1994). The male individual fully supplies the dietary requirements for the female from the beginning of incubation until about two weeks after the eggs hatch, however, when there is limited food availability, the females hunt earlier after the eggs have hatched (Durant et al. 2004).

By nature, owls (Tytonidae) do not build their own nests. They nest in tree holes or in buildings where there is little human activity and use artificial cages, furthermore, they do not defend the foraging area from other owl pairs but the territory around their nest (Martin et al. 2005). The spread of owls is seen based on the distribution of nest boxes in the research location. Moreover, increasing the Barn owl population on agricultural land reduces damage and economic losses from rodent attacks (Khan et al. 2014).

Conclusively, the Sulawesi Masked-owl ( $T$. rosenbergii) lays 2-6 eggs in one reproductive cycle with an average hatching percentage of $80.77 \%$. Furthermore, the percentage of chicks that survived to have full feathers is $51 \%$ and they learn to fly at the age of eight weeks after hatching. The Sulawesi masked owl prey on 1-4 rats per night its activity is mostly outside the nest box, except during the breeding period. Finally, $T$. rosenbergii has the potential to become a biological control agent for rats in an oil palm plantation in Sulawesi.

\section{ACKNOWLEDGEMENTS}

The authors are grateful to the management PT. Astra Agro Lestari for all support and permission to conduct field research in their oil palm plantation. The authors are also grateful to Dwi Ersanto, M. Syarifudin, M.F. Erikson, Gilang Fajar Ramadhan, Muhammad Ikhsan, and Hanif Abdirrahim, for providing support during the field research.

\section{REFERENCES}

Abidin CMRZ, Hafidzi MN, Hamid NH, Salim H. 2016. Propagation of Barn owl in an oil palm plantation of Sabah: FGV's experience; Proceedings of $9^{\text {th }}$ International Conference on Plant Protection in the Tropics ( $9^{\text {th }}$ ICPPT). Hilton Hotel, Kuching Sarawak, 3-5 August 2016. [Malaysia].

Abidin CMRZ, Hafidzi MN, Hamid NH, Salim H. 2017. Diet preferences and reproduction of translocated Barn owl (Tyto alba javanica) in captivity. J. Oil Palm Res. 29 (3): 333-342.

Adejumo IO. 2019. Strategies of owls reproduction. Department of Animal Science, Federal University Gashua, Gashua, Nigeria. DOI: 10.5772/intechopen.82425
Bank L, Haraszthy L, Horvath A, Horvath GM. 2019. Nesting success and productivity of the common Barn owl (Tyto alba): Results from a nest box installation and long-term breeding monitoring program in Southern Hungary. Ornis Hung 27 (1): 1-31.

BirdLife International. 2016. Tyto rosenbergii. The IUCN Red List of Threatened Species 2016: e.T22688489A93198600. 10.2305/IUCN.UK.20163.RLTS.T22688489A 93198600.en

Bunn DS, Warburton AB. 1997. Observations of breeding Barn owls. Br. Birds 70: 246-256.

Chausson A, Henry I, Almasi B, Roulin A. 2013. Barn owl (Tyto alba) breeding biology in relation to breeding season climate. J Ornithol 155: $273-281$

Datta SC. 2019. Enriched school environment for the effective bio-activity of Barn owl. IJHAF 3 (3): 119-126.

Durant JM, Gendner JP, Handrich Y. 2004. Should i brood or should i hunt: A female Barn owl's dilemma. Can J Zool 82: 1011-1016.

Durant JM, Hjermann DO, Handrich Y. 2013. Diel feeding strategy during breeding in male Barn owls (Tyto alba). J. Ornithol 154: 863-869.

Elliott JE, Hindmarch S, Albert CA, Emery J, Mineau P, Maisonneuve. 2014. Exposure pathways of anticoagulant rodenticides to nontarget wildlife. Environ. Monit. Assess 186: 895-906.

Horak KE, Volker SF, Camptom CM. 2015. Increased diphacinone and chlorophacinone metabolism in previously exposed wild-caught voles, Microtus californicus. J Crop Prot 78: 35-39.

Hovárth A, Morvai A, Hovárth GF. 2018. Food-niche pattern of the Barn owl (Tyto alba) in intensively cultivated agricultural landscape. Ornis Hung 26 (1): 27-40.

Ikhsan M, Priyambodo S, Nurmansyah A, Hendarjanti H, Sahari B. 2020. Species diversity, abundance and damaged caused by rats in oil palm plantation in West and Central Sulawesi, Indonesia. Biodiversitas 21 (2): 5632-5639.

Khan HA, Javed M, Sohail M, Asif M. 2014. Dietary habits of the Barn owl (Tyto alba) in agricultural farmland of Faisalabad Pakistan. Int J Curr Microbiol App Sci 3 (8): 211-218.

Mainwaring MC. 2015. The use of man-made structures as nesting sites by birds: A review of the cost and benefits. J Nat Conserv 25: 17-22.

Marti CD. 2010. Dietary trends of Barn owls in an agricultural ecosystem in Northern Utah. Wilson J. Ornithol 122 (1): 60-67.

Martin JM, Raid RN, Branch LC. 2005. Barn Owl (Tyto alba). Department of Wildlife Ecology and Conservation, Florida Cooperative Extension Service, Institute of Food and Agricultural Sciences (IFAS), University of Florida, Miami.

Milchev B. 2015. Diet of Barn owl (Tyto alba) in Central South Bulgaria as influenced by landscape structure. Turkish J Zool 39 (5): 933-940.

Nager RG. 2006. The challenges of making eggs. Ardea 94 (3): 323-346.

Oil World. 2019. Oil World Annual 2019. ISTA Mielke GmbH, Germany.

Puan CL, Goldizen AW, Zakaria M, Hafidzi MN, Baxter GS. 2011. Absence of differential predation on rats by Malaysian Barn-owls in oil palm plantation. J Raptor Res 45 (1): 71-78.

Rabou AFNA. 2019. Bird fauna encountered at the main campus of the Islamic University of Gaza, Gaza City, Palestine. Biodiversitas 20 (2): 604-614.

Rajagukguk BH. 2014. Pemanfaatan burung hantu (Tyto alba) untuk pengendalian hama tikus di perkebunan kelapa sawit. J Saintech 6 (4): 1-7. [Indonesian]

Scott DE. 2016. Raptor, medicine, surgery, and rehabilitation second edition. CAB International Publisher, Wallingford, UK.

Syaufi S, Ravindran S, Hamid NH, Abidin CRMZ, Ahmad H, Ahmad AH, Salim H. 2020. Diet composition of introduced Barn owl (Tyto alba javanica) in urban area in comparison with agriculture settings. $\mathrm{J}$ Urban Ecol 6 (1): juz025, DOI: 10.1093/jue/juz025.

Taylor IR. 1994. Barn owls: Predator-prey relationships and conservation. Cambridge University Press, Cambridge, UK.

Verwilghen A. 2015. Rodent pest management and predator communities in oil palm plantations in Indonesia: A comparison of two contrasting systems [Thesis]. Universite de Franche, Comte. [French]

Wendt CA, Johnson MD. 2017. Multi-scale analysis of Barn owl nest box selection on Nava Valley vineyards. Agric Ecosyst Environ 247: 7583 .

Wood BJ, Fee CG. 2003. A critical review of the development of rat control in Malaysian agriculture since the 1960s. J Crop Prot 2 (3): 445-461. 